\title{
Cláusulas abusivas entre profesionales: el caso del agente comercial en Colombia**
}

DOI: dx.doi.org/10.15425/2017.355

\section{Resumen}

En principio, al ser las cláusulas abusivas unas previsiones contractuales que rompen el equilibrio entre las prestaciones a cargo de las partes en un contrato, el derecho de consumo se ha ocupado de ellas para ayudar a determinar la asimetría de una relación contractual sin necesidad de acudir a los jueces. Sin embargo, los efectos que el Estatuto del Consumidor da a este tipo de cláusulas quedaron circunscritos a las relaciones en las que participen consumidores, excluyendo las relaciones entre comerciantes. Sin embargo, la jurisprudencia ha venido extendiendo el ámbito de aplicación de esta protección a los contratos asimétricos celebrados únicamente entre comerciantes, lo cual va en armonía con la tendencia legislativa internacional. La pregunta que se plantea en este estudio es si en Colombia debería seguirse esta misma tendencia a través de una reforma legislativa en ese sentido. Para ello se estudia un caso en particular, el del agente comercial colombiano que es contratado por un agenciado extranjero para desarrollar dicha actividad en el territorio nacional. En estos contratos suele existir una cláusula de renuncia al pago de la prestación conocida como cesantía comercial en caso de terminación unilateral

* Doctora en Derecho de la Universidad Panthéon-Assas, Paris 2. Actualmente, profesora investigadora de la Fundación Universitaria Cervantes San Agustín. Correo electrónico: betty.martinez@ unicervantes.edu.co.

** Este artículo es resultado del proyecto de investigación denominado "La reforma de las cláusulas abusivas en Colombia", iniciado desde junio de 2018, dentro del Grupo de Investigación Communitas Sapientiae, de la Fundación Universitaria Cervantes San Agustín. 
del contrato. No obstante, comparada esta cláusula con lo que establece la legislación colombiana, se demuestra que tal cláusula es contraria a las reglas de orden público de Colombia, así como de otros países extranjeros, en particular los países de la Unión Europea. Contrariar el orden público es uno de los criterios admitidos por la jurisprudencia colombiana para aplicar la protección de las cláusulas abusivas a los comerciantes; sin embargo, la autora demuestra cómo es la misma Corte, por motivos políticos y de oportunidad, la que se niega a proteger al agente colombiano. En consecuencia, dejar solo a la jurisprudencia la tarea de desarrollar el ámbito de aplicación de las cláusulas abusivas vía su interpretación es insuficiente, justificándose así la necesidad de una reforma al Estatuto de Protección al Consumidor para incluir en ella a los comerciantes.

\section{Palabras clave}

Cláusulas abusivas, profesionales, agencia mercantil, orden público, cesantía mercantil, consumidores. 


\title{
Abusive clauses among professionals: the case of the commercial agent in Colombia
}

\begin{abstract}
In principle, as abusive clauses are contractual provisions that break the balance between the benefits payable by the parties to a contract, consumer law has taken them up to help determine the asymmetry of a contractual relationship without having to go to the judges. However, jurisprudence has been extending the scope of this protection to asymmetric contracts concluded only between merchants, which is in harmony with the international legislative trend. The question that arises in this study is to know if this same trend should be followed in Colombia through legislative reform in that regard. For this, this paper studies the case of the Colombian commercial agent who is hired by a foreign agency to carry out its activity in the national territory. In these contracts, Colombian agent usually waives to the severance in case of unilateral termination of the contract. Notwithstanding the foregoing, comparing this waiver clause with what is established by Colombian legislation, it results that such clause is contrary to the rules mandatory in nature of Colombia, as well as other foreign countries, in particular, the countries of the European Union. One of the criteria admitted by Colombian jurisprudence to apply the protection of abusive clauses to merchants is to contrary rules mandatories in nature. However, the author demonstrates what the Court itself is like, for political and opportunity reasons, which refuses to Protect the Colombian agent. Consequently, leaving only the jurisprudence to develop the scope of the abusive clauses via their interpretation is insufficient, thus justifying the need for a reform of the Consumer Protection Statute to include merchants in it.
\end{abstract}

\section{Keywords}

Abusive clauses, professionals, commercial agency, rules mandatories in nature, commercial severance, consumers. 


\section{Introducción}

En la lucha interminable para lograr la igualdad entre contratantes mediante la eliminación de las cláusulas abusivas ${ }^{1}$, el debate de si éstas también se encontrarían en los contratos celebrados entre comerciantes tiene ya algunos años de vigencia. En efecto, desde hace más de una década enseñaba Bianca que "El abuso del poder contractual también perjudica el mercado cuando se ejercita en las relaciones entre empresarios, pues penaliza las categorías de productores y comerciantes víctimas de tal poder, y altera el libre juego de intercambios e inversiones"2.

En principio, al ser las cláusulas abusivas una herramienta propia del derecho de consumo para determinar la asimetría de una relación contractual, la protección consistente en tenerlas como no escritas, o nulas de pleno derecho, solo podría ser aplicada a contratos celebrados por consumidores ${ }^{3}$, de allí que éstas sean expresamente reguladas por los estatutos de protección al consumidor ${ }^{4}$.

Así, aunque se ha criticado por no hacerlo de manera armónica ${ }^{5}$, en Colombia el artículo 42 de la Ley 1480 de 2011 define expresamente a las cláusulas abusivas como aquellas que "producen un desequilibrio injustificado en perjuicio del consumidor y las que, en las mismas condiciones, afecten el tiempo, modo o lugar en que el consumidor puede ejercer sus derechos".

Sin embargo, la doctrina no es unánime sobre el punto de estimar suficiente la protección que el legislador ha establecido respecto de la noción y los efectos de una cláusula abusiva ${ }^{6}$, y se ha preocupado por esclarecer los criterios para reconocer una cláusula abusiva, más allá de lo establecido en el Estatuto de Protección al Consumidor. José Gual, por ejemplo, nos propone la siguiente definición:

Betty Martínez-Cárdenas, "Protección del consentimiento y reglas especiales del consumo: La lucha interminable contra las cláusulas abusivas", en Condiciones generales de la contratación y cláusulas abusivas, coordinado por Francisca Barrientos Camus (Santiago: Ediciones Universidad Diego Portales, 2014), 69. (Bogotá: Universidad Externado de Colombia, 2007), 417.

3 Javier Lete, "Les conditions générales des contrats dans le projet espagnol de réforme du droit des obligations", en Les clauses abusives, coordinado por Yves Picod, Denis Mazeaud y Elena Lauroba (Perpignan: Société de Législation Comparée, 2012), 54. Jean Calais-Auloy y Henri Temple, Droit de la Consommation (Paris: Dalloz, 2015), 164. ¿compatibilidad o dicotomía?", Prolegómenos 16, n. 32 (2013), 159, https://doi.org/10.18359/ dere.766. 
[...] aquella que resulta predispuesta por una de las partes, quien ejerce un cierto poder contractual derivado, por lo general, de una posición dominante y que de hecho resulta impuesta a la otra parte, quien se encuentra en una condición de dependencia económica o debilidad [...] generando con dicha disposición un desequilibrio normativo, es decir, de los derechos y obligaciones, pero que además debe ser de carácter importante o significativo [...] [ [énfasis agregado].

A partir de esta definición, y en particular los adjetivos destacados, encontramos las características más relevantes de este tipo de cláusulas. Esta definición atiende tanto al nacimiento como a los efectos de la cláusula.

En relación con cómo nacen, al decir el adjetivo "predispuesta" hace referencia a que la cláusula hubiese sido extendida por la otra parte y que a ella el contratante, víctima del abuso, hubiese consentido por adhesión ${ }^{8}$. De allí que tome importancia la posición de poder o de dominio que la parte que extiende la cláusula ejerce sobre su co-contratante. En consecuencia, partiendo de esta definición, difícilmente podría aceptarse la existencia de cláusulas abusivas fruto de una discusión entre las partes sobre el texto de ella. Por esa razón, la cláusula resulta "de hecho" impuesta a aquella de las partes que se encuentra en situación de asimetría, sea económica o física, esto puede ser tanto en conocimientos como en literalmente fuerza física o temor que pueda crear la parte fuerte sobre el otro contratante 9 .

En relación con los efectos, el primero que las caracteriza es la creación de un desequilibrio normativo ${ }^{10}$. El profesor Gual explica que por esta expresión se refiere a que haya un desbalance entre derechos y obligaciones ${ }^{11}$, lo cual nos lleva al carácter de bilateral, oneroso y conmutativo que debe tener el contrato para poder ser reequilibrado ${ }^{12}$.

Además de caracterizar a este tipo de cláusulas tanto por su origen como por sus efectos, otra parte de la doctrina agrega una categoría adicional: la necesidad de que este tipo de cláusulas se encuentre en las relaciones entre consumidor y comerciantes. En efecto, la gran mayoría de los textos legales que las regulan atañe

7 José Manuel Gual Acosta, "Las cláusulas abusivas - Evolución hacia una noción”, Revista Verba luris 11, n. ${ }^{\circ} 36$ (2016), 113-120, https://doi.org/10.18041/0121-3474/verbaiuris.36.1017.

Camilo Rodríguez Yong, Una aproximación a las cláusulas abusivas (Bogotá: Universidad del Rosario y Legis, 2013), 52. Martínez-Cárdenas (Bogotá: Universidad del Rosario, 2009), 33 y 69.

10 José Manuel Gual Acosta, "El control sobre las cláusulas abusivas un régimen en evolución”. IUSTA, n. ${ }^{\circ} 30$ (2009), 17, https://doi.org/10.15332/s1900-0448.2009.0030.01.

11 Gual, "Las cláusulas abusivas”, 123.

12 Rocha, Lecciones sobre Derecho Civil Obligaciones, 27. 
al derecho del consumidor ${ }^{13}$. En Colombia, en particular, el campo de aplicación legal de esta protección está en principio reservado al consumidor ${ }^{14}$. Sin embargo, frente a una jurisprudencia que ha venido extendiendo el ámbito de aplicación a los contratos asimétricos que no fueron consentidos por adhesión entre comerciantes, y a una tendencia internacional que, como se verá más adelante, va en este mismo sentido, la pregunta que se plantea es si este tipo de protección podría ser ampliada al ámbito mercantil a través de una reforma legislativa en Colombia.

En efecto, otras legislaciones ya han previsto la aplicación de las sanciones contra las cláusulas abusivas a los comerciantes. Así, en España, por ejemplo, el párrafo segundo del artículo 3 TRLGCU establece que "son también consumidores a efectos de esta norma las personas jurídicas y las entidades sin personalidad jurídica que actúen sin ánimo de lucro en un ámbito ajeno a una actividad comercial o empresarial". En Chile, la Ley 20.146 la extiende a las pequeñas y medianas empresas; en tanto que en Francia el numeral segundo del artículo L442-6 del Código de Comercio consagra muy claramente que "incurre en responsabilidad el productor, comerciante, industrial o persona matriculada como tal que someta o intente someter a otro co-contratante comerciante al cumplimiento de obligaciones que creen un desequilibrio significativo en los derechos y obligaciones de las partes"15.

Yves Picod, "Les clauses abusives dans les projects de réforme français", en Les clauses abusives, coordinado por Yves Picod, Denis Mazeaud y Elena Lauroba (Perpignan: Société de Législation Comparée, 2012), 43.

Rodríguez, Una aproximación a las cláusulas abusivas, 27.

Realmente este artículo regula la asimetría desde múltiples perspectivas. A continuación transcribo el texto original en francés: “I. - Engage la responsabilité de son auteur et l'oblige à réparer le préjudice causé le fait, par tout producteur, commerçant, industriel ou personne immatriculée au répertoire des métiers:

$1^{\circ}$ D'obtenir ou de tenter d'obtenir d'un partenaire commercial un avantage quelconque ne correspondant à aucun service commercial effectivement rendu ou manifestement disproportionné au regard de la valeur du service rendu. Un tel avantage peut notamment consister en la participation, non justifiée par un intérêt commun et sans contrepartie proportionnée, au financement d'une opération d'animation ou de promotion commerciale, d'une acquisition ou d'un investissement, en particulier dans le cadre de la rénovation de magasins, du rapprochement d'enseignes ou de centrales de référencement ou d'achat ou de la rémunération de services rendus par une centrale internationale regroupant des distributeurs. Un tel avantage peut également consister en une globalisation artificielle des chiffres d'affaires, en une demande d'alignement sur les conditions commerciales obtenues par d'autres clients ou en une demande supplémentaire, en cours d'exécution du contrat, visant à maintenir ou accroître abusivement ses marges ou sa rentabilité;

$2^{\circ}$ De soumettre ou de tenter de soumettre un partenaire commercial à des obligations créant un déséquilibre significatif dans les droits et obligations des parties;

$3^{\circ}$ D'obtenir ou de tenter d'obtenir un avantage, condition préalable à la passation de commandes, sans l'assortir d'un engagement écrit sur un volume d'achat proportionné et, le cas échéant, d'un service demandé par le fournisseur et ayant fait l'objet d'un accord écrit; 


\title{
En Colombia, la extensión de esta protección por parte de la Corte Suprema
} de Justicia se ha hecho evidente, en la medida en que esta corte ha venido desarrollando en los últimos veinte años los criterios de abusividad que se aplican tanto a consumidores como a comerciantes, sea que hayan adquirido sus obligaciones a través de un contrato de adhesión, como de uno negociado.

\begin{abstract}
$4^{\circ}$ D'obtenir ou de tenter d'obtenir, sous la menace d'une rupture brutale totale ou partielle des relations commerciales, des conditions manifestement abusives concernant les prix, les délais de paiement, les modalités de vente ou les services ne relevant pas des obligations d'achat et de vente;

$5^{\circ}$ De rompre brutalement, même partiellement, une relation commerciale établie, sans préavis écrit tenant compte de la durée de la relation commerciale et respectant la durée minimale de préavis déterminée, en référence aux usages du commerce, par des accords interprofessionnels. Lorsque la relation commerciale porte sur la fourniture de produits sous marque de distributeur, la durée minimale de préavis est double de celle qui serait applicable si le produit n'était pas fourni sous marque de distributeur. A défaut de tels accords, des arrêtés du ministre chargé de l'économie peuvent, pour chaque catégorie de produits, fixer, en tenant compte des usages du commerce, un délai minimum de préavis et encadrer les conditions de rupture des relations commerciales, notamment en fonction de leur durée. Les dispositions qui précèdent ne font pas obstacle à la faculté de résiliation sans préavis, en cas d'inexécution par l'autre partie de ses obligations ou en cas de force majeure. Lorsque la rupture de la relation commerciale résulte d'une mise en concurrence par enchères à distance, la durée minimale de préavis est double de celle résultant de l'application des dispositions du présent alinéa dans les cas où la durée du préavis initial est de moins de six mois, et d'au moins un an dans les autres cas;
\end{abstract}

$6^{\circ}$ De participer directement ou indirectement à la violation de l'interdiction de revente hors réseau faite au distributeur lié par un accord de distribution sélective ou exclusive exempté au titre des règles applicables du droit de la concurrence;

$7^{\circ}$ D'imposer une clause de révision du prix, en application du cinquième alinéa du I de l'article L. 441-7 ou de l'avant-dernier alinéa de l'article L. 441-7-1, ou une clause de renégociation du prix, en application de l'article L. 441-8, par référence à un ou plusieurs indices publics sans rapport direct avec les produits ou les prestations de services qui sont l'objet de la convention;

$8^{\circ}$ De procéder au refus ou retour de marchandises ou de déduire d'office du montant de la facture établie par le fournisseur les pénalités ou rabais correspondant au non-respect d'une date de livraison ou à la non-conformité des marchandises, lorsque la dette n'est pas certaine, liquide et exigible, sans même que le fournisseur n'ait été en mesure de contrôler la réalité du grief correspondant;

$9^{\circ}$ De ne pas communiquer ses conditions générales de vente, dans les conditions prévues à l'article L. 441-6, à tout acheteur de produits ou tout demandeur de prestations de services qui en fait la demande pour l'exercice d'une activité professionnelle;

$10^{\circ}$ De refuser de mentionner sur l'étiquetage d'un produit vendu sous marque de distributeur le nom et l'adresse du fabricant si celui-ci en a fait la demande conformément à l'article L. 112-6 du code de la consommation;

$11^{\circ}$ D'annoncer des prix hors des lieux de vente, pour un fruit ou légume frais, sans respecter les règles définies aux II et III de l'article L. 441-2 du présent code;

$12^{\circ}$ De passer, de régler ou de facturer une commande de produits ou de prestations de services à un prix différent du prix convenu résultant de l'application du barème des prix unitaires mentionné dans les conditions générales de vente, lorsque celles-ci ont été acceptées sans négociation par l'acheteur, ou du prix convenu à l'issue de la négociation commerciale faisant l'objet de la convention prévue à l'article L. 441-7, modifiée le cas échéant par avenant, ou de la renégociation prévue à l'article L. 441-8.

$13^{\circ}$ De soumettre ou de tenter de soumettre un partenaire commercial à des pénalités pour retard de livraison en cas de force majeure. II. - Sont nuls les clauses ou contrats prévoyant pour un producteur, un commerçant, un industriel ou une personne immatriculée au répertoire des métiers, la possibilité: 
A continuación examinaremos los principales criterios de abusividad formulados por la Corte Suprema de Justicia y el simultáneo fracaso que dicha extensión ha tenido por una tendencia jurisprudencial de los últimos años, tomando como ejemplo el contrato de agencia mercantil.

\section{Principales criterios de abusividad en cláusulas entre comerciantes adoptados por la Corte Suprema de Justicia de Colombia}

Estos criterios son tres. Así, una cláusula sería abusiva entre comerciantes, en razón del tipo de desequilibrio que generan (A); de que violan la buena fe en sentido objetivo (B) y son contrarias al orden público (C).

\section{A) Cláusulas que generan un desequilibrio normativo (no económico) importante}

La doctrina es unánime en el sentido de dotar el carácter de abusiva a una cláusula que genera un desequilibrio significativo en el contrato ${ }^{16}$. Se requiere que este desequilibrio sea normativo, no económico 17 . "En efecto, si el carácter abusivo concierne la ausencia de adecuación entre el precio o la remuneración y la cosa o la prestación del servicio, no se trataría de un desequilibrio significativo, sino de un problema económico"18, podríamos decir que es una consecuencia de la autonomía

a) De bénéficier rétroactivement de remises, de ristournes ou d'accords de coopération commerciale;

b) D'obtenir le paiement d'un droit d'accès au référencement préalablement à la passation de toute commande;

c) D'interdire au cocontractant la cession à des tiers des créances qu'il détient sur lui;

d) De bénéficier automatiquement des conditions plus favorables consenties aux entreprises concurrentes par le cocontractant;

e) D'obtenir d'un revendeur exploitant une surface de vente au détail inférieure à 300 mètres carrés qu'il approvisionne mais qui n'est pas lié à lui, directement ou indirectement, par un contrat de licence de marque ou de savoir-faire, un droit de préférence sur la cession ou le transfert de son activité ou une obligation de non-concurrence postcontractuelle, ou de subordonner l'approvisionnement de ce revendeur à une clause d'exclusivité ou de quasi-exclusivité d'achat de ses produits ou services d'une durée supérieure à deux ans". 
de la voluntad de las partes y, en algunos casos, la sanción que le correspondería es la de la lesión enorme.

El desequilibrio significativo, según se trate de una cláusula prevista por la legislación como abusiva, o no, se apreciará en abstracto o en concreto, teniendo en cuenta todas sus cláusulas del contrato y las circunstancias que rodearon la celebración de este.

\section{Análisis in abstracto o in concreto}

Esto depende de si se trata de una cláusula a la que el legislador denotó como abusiva, o no. En el primer caso, el análisis debe hacerse in abstracto. Sin consideración a ninguna otra condición del contrato. En efecto, en estos casos, el juez no debe entrar en las circunstancias específicas de la contratación evaluada, sino que se compararía al consumidor con un estándar general como, por ejemplo, a lo que habría hecho un buen padre de familia ${ }^{19}$.

Por el contrario, si se tratara de cláusulas incluidas en lo que en otras legislaciones se conoce como "lista gris" de cláusulas abusivas, o en contratos que no son de adhesión, sino negociados, el análisis habría que hacerlo in concreto. La razón de ello es que el desequilibrio significativo no se presume en este caso, sino que debe ser probado.

En consecuencia, en principio, quien está legitimado para invocar el carácter abusivo de una cláusula es el consumidor, este es "Toda persona natural o jurídica que, como destinatario final, adquiera, disfrute o utilice un determinado producto, cualquiera que sea su naturaleza para la satisfacción de una necesidad propia, privada, familiar o doméstica y empresarial cuando no esté ligada intrínsecamente a su actividad económica. Se entenderá incluido en el concepto de consumidor el de usuario" ${ }^{20}$. En este caso, si la cláusula en cuestión hace parte de una de las definidas como abusivas por el catálogo respectivo, la presunción de abusiva es de pleno derecho. Por ello su análisis se hace in abstracto.

Sin embargo, la jurisprudencia de la Corte Suprema de Justicia ha extendido esta protección a los comerciantes cuando éstos contratan un objeto que está por fuera de su actividad habitual ${ }^{21}$, ya que en este caso los jueces tienden a considerar que el profesional se encuentra en el mismo estado de ignorancia que un consu- 
midor ${ }^{22}$. No es el comerciante quien podría valerse de la presunción de abusividad que trae el catálogo del estatuto de protección al consumidor respectivo, porque no le sería aplicable. No obstante, el comerciante puede probar dicho carácter abusivo de la cláusula, según las demás circunstancias que acompañaron la celebración del contrato. Por ello el análisis de dicha cláusula se hace in concreto.

\section{Teniendo en cuenta todas las demás cláusulas del contrato y apreciación de todas las circunstancias que rodearon su conclusión}

El análisis in concreto implica tener en cuenta todas las otras cláusulas del contrato. Así fue como procedió, por ejemplo, la Sala Civil de la Corte Suprema de Justicia al analizar un contrato de cuenta corriente entre un comerciante y un banco, para determinar la responsabilidad del banco por haber pagado cuatro cheques, por un valor cercano a los quinientos millones de pesos, desconociendo la ley de circulación del título valor al no abonar el importe del cheque en la cuenta corriente, pagarlos indebidamente por ventanilla, además de diligenciarlos en forma manuscrita y sin el sello registrado o con uno diferente al registrado ${ }^{23}$. El banco argumentó en su defensa, entre otras excepciones, la de caducidad de la acción. Sin embargo, la Corte no se limitó a comparar el precio del contrato con el servicio prestado, sino que advirtió que el banco había reducido en el contrato el plazo de caducidad del cheque, así que, además de declarar la responsabilidad del banco, estimó que este tipo de cláusula era abusiva:

[E]s lo cierto que una cláusula como ésta sobre la cual pretende la entidad bancaria sustentar la excepción que se analiza, al dejar en manos del ente financiero el inicio del conteo del corto término de 15 días que tiene el cuentahabiente para objetar un extracto, que además le llega después de que ese plazo ha comenzado, cláusula que pone en clara situación desventajosa al cuentahabiente, quien por lo general no la discute ni pacta por cuanto tal estipulación se encuentra prevista en un clausulado preestablecido por el banco, debe ser considerada como cláusula abusiva, y por este aspecto también ineficaz ${ }^{24}$.

Pasaremos ahora a estudiar el segundo criterio, la violación de la buena fe objetiva.

Valette-Ercole, "Les clauses abusives", 175.

Corte Suprema de Justicia de Colombia. Sala de Casación Civil. Sentencia del 24 de febrero de 2015, MP: Jesús Vall de Rutén Ruiz. 


\section{B) Cláusulas que violan la buena fe en sentido objetivo}

Por esto, comprende la Corte Suprema de Justicia a las cláusulas que "lesionen los requerimientos emergentes de la buena fe negocial -vale decir, que se quebrante este postulado rector desde una perspectiva objetiva"25. Pese a ser considerada por algunos una expresión que conduce a equívocos, esta buena fe ha sido definida por un amplio sector de la doctrina como una herramienta jurídica para soportar los distintos deberes de conducta que, previo a la celebración del contrato, y durante su celebración ${ }^{26}$, los artículos 863 y 871 del Código de Comercio les imponen cumplir. Estos deberes son tres, a saber: el de información, el de discreción y el de coherencia ${ }^{27}$.

En consecuencia, las cláusulas que eximieran del deber de información a quien por ley le corresponde, o negaran el derecho a ser informado del contratante que por sus propios medios no puede informarse; las que eximieran de responsabilidad por la revelación de la información confidencial compartida entre las partes con el fin de celebrar o ejecutar el contrato; y las que creen una apariencia que en la práctica conducirá a una consecuencia diferente, serían abusivas.

\section{C) Cláusulas que son contrarias al orden público}

Se trata de cláusulas que disponen lo contrario a lo previsto en disposiciones legales de carácter imperativo y sobre las cuales no podía disponerse de esa forma ${ }^{28}$. Las reglas que establecen términos de caducidad y prescripción son unas de ellas, por ello el que el banco, en el ejemplo anterior, hubiera reducido el término de caducidad a través de una cláusula, hacía que ésta contrariara el orden público.

En materia de protección al consumidor financiero, por ejemplo, van contra el orden público las cláusulas que obliguen al usuario del servicio a utilizar un medio determinado de solución alternativa de conflictos ${ }^{29}$.

25 Corte Suprema de Justicia de Colombia. Sala de Casación Civil. Sentencia del 2 de febrero de 2001, MP: Carlos Ignacio Jaramillo Jaramillo.

26 Vladimir Monsalve-Caballero y Diana Paola Rodado-Barreto, "La integración de la buena fe objetiva en la etapa de formación de los contratos de consumo", Vniversitas 60, n. ${ }^{\circ} 122$ (2011), 483-517, https://doi.org/10.11144/Javeriana.vj60-122.ibfo.

Betty Martínez-Cárdenas y Hernando Tapias-Rocha, "La transformación del derecho privado en Colombia”, Revista de Derecho, n. ${ }^{\circ} 45$ (2016), 52, http://dx.doi.org/10.14482/dere.45.7970.

Cláusulas "[...] que impongan la obligación de utilizar de manera exclusiva un determinado mecanismo alternativo de solución de conflictos para resolver las controversias entre consumidores financieros y entidades vigiladas: numeral 10.1.2 de la Circular 039 de 2011, que por autoridad del literal d del artículo 12 de la Ley 1328 de 2009 define las cláusulas y prácticas abusivas en el sector financiero, se tiene lo siguiente". 
Sin embargo, en materia comercial también pueden existir cláusulas que van contra el orden público, como las siguientes:

- $\quad$ en los contratos celebrados con extranjeros, fuera del territorio nacional, pero cuyas obligaciones serían ejecutables en Colombia, serían de este tipo las cláusulas de jurisdicción que impongan que al contrato lo rige una determinada ley extranjera, ya que esto va en contra de lo establecido expresamente por el artículo 869 del Código de Comercio, según el cual "La ejecución de los contratos celebrados en el exterior que deban cumplirse en el país, se regirá por la ley colombiana";

- las cláusulas de jurisdicción que impongan que en caso de diferencias entre las partes respecto de las obligaciones que deben ejecutarse en Colombia, el juez que debe dirimirlas es un juez de jurisdicción extranjera, ya que las reglas procesales son de orden público ${ }^{30}$;

- las cláusulas de irresponsabilidad, es decir que exoneran de responsabilidad a aquel que ha cometido el daño con dolo;

- las cláusulas que establecen renuncias a derechos que por ley le corresponden al co-contratante, por ser estos irrenunciables; $y$

- $\quad$ las que establecen presunciones de consentimiento.

Ahora bien: la necesidad de una reforma legislativa que contenga estos criterios se hace más clara cuando se compara este desarrollo jurisprudencial con su aplicación fallida en un caso práctico concreto.

En efecto, a continuación veremos cómo este desarrollo jurisprudencial fracasa por cuenta de un único fallo que en lugar de aplicar esta teoría a la práctica, se pliega a intereses coyunturales de conveniencia internacional en uno de los contratos más importantes de la vida mercantil, la agencia comercial.

\section{El fracaso de la teoría de las cláusulas abusivas entre comerciantes: el caso de la agencia mercantil}

Ahora veremos cómo, a pesar del esfuerzo de los jueces por extender el ámbito de aplicación de las cláusulas abusivas a los comerciantes, dicho esfuerzo falló por 
parte de la misma Corte Suprema de Justicia frente a uno de los contratos más frecuentes en materia mercantil: la agencia.

En efecto, como vimos en la sección anterior, a la luz de la teoría de las cláusulas abusivas, cualquier cláusula predispuesta por una de las partes para hacer que la otra renuncie a uno de los derechos que por ley le corresponde, es abusiva. Frente a ello, dentro del marco de la agencia mercantil, cabe entonces preguntarnos si es de este tipo la cláusula mediante la cual aparece que el agente renuncia a la prestación denominada "cesantía comercial” prevista en el artículo 1324.

Para ello, recordemos el tenor de la norma:

Art. 1324. Terminación de la agencia

El contrato de agencia termina por las mismas causas del mandato, y a su terminación el agente tendrá derecho a que el empresario le pague una suma equivalente a la doceava parte del promedio de la comisión, regalía o utilidad recibida en los tres últimos años, por cada uno de vigencia del contrato, o al promedio de todo lo recibido, si el tiempo del contrato fuere menor.

Además de la prestación indicada en el inciso anterior, cuando el empresario revoque o dé por terminado unilateralmente el contrato, sin justa causa comprobada, deberá pagar al agente una indemnización equitativa, fijada por peritos, como retribución a sus esfuerzos para acreditar la marca, la línea de productos o los servicios objeto del contrato. La misma regla se aplicará cuando el agente termine el contrato por justa causa imputable al empresario.

Para la fijación del valor de la indemnización se tendrá en cuenta la extensión, importancia y volumen de los negocios que el agente adelantó en desarrollo del contrato.

Si es el agente el que da lugar a la terminación unilateral del contrato por justa causa comprobada, no tendrá derecho a indemnización o pago alguno por este concepto.

Ahora bien: la doctrina tradicional ha examinado este punto a la luz de las reglas comunes contractuales, y no al del desarrollo jurisprudencial que extiende la protección del derecho de consumo relativa a las cláusulas abusivas a los comerciantes.

En efecto, ante la pregunta de saber si son válidas o no las cláusulas mediante las cuales las partes en un contrato de agencia pactan que el agente renuncia a la "cesantía comercial", la doctrina colombiana ha sostenido un largo debate.

Este debate consiste en que una parte de la doctrina considera que dicho pacto no es válido, por ser el artículo 1324 de orden público, lo cual significa que, sobre sus efectos, las partes no pueden pactar en contrario dentro de sus 
estipulaciones contractuales ${ }^{31}$. Sin embargo, la otra parte de la doctrina considera que sí es posible hacer este tipo de pactos, justamente por el argumento opuesto, consistente en que la misma regla no tiene carácter imperativo ${ }^{32}$.

Sin embargo, la Corte Suprema de Justicia hasta el año 2011 había mantenido la postura de que esta regla era de orden público, y, por ende, contenía una prestación irrenunciable ${ }^{33}$, que posiblemente se podía pagar incluso a lo largo del contrato, pero que por ningún motivo podía dejarse de pagar ${ }^{34}$. Sin embargo, en el 2011, en un momento en el que la historia muestra que Colombia venía siendo presionada por las negociaciones del Tratado de Libre Comercio

31 José Ignacio Narváez, Introducción al Derecho Mercantil (Bogotá: Ediciones Bonnet, 1976), 283 y ss.; Álvaro Pérez Vives, Comentarios al Código de Comercio, vol. 1 (Bogotá: Colegas, 1980), 243; Tribunal Superior de Medellín. Sentencia del 6 de diciembre de 1978, MP: Horacio Montoya; Corte Suprema de Justicia de Colombia. Sala de Casación Civil. Sentencia del 28 de febrero de 2005. MP: Carlos Ignacio Jaramillo.

32 Gabriel Escobar Sanín, Negocios de Sustitución, tomo I (Bogotá: Universidad Externado de Colombia, 1987), 439; José Vicente Hurtado-Palomino. "La influencia del TLC con Estados Unidos en la evolución del alcance del concepto de orden público: la renunciabilidad de la mal llamada cesantía comercial", Díkaion Revista de Fundamentación Jurídica 21, n. ${ }^{\circ} 1$ (2012), 255-284, https://dikaion. unisabana.edu.co/index.php/dikaion/article/view/2378/3099; Carlos Julio Giraldo Bustamante, "La agencia comercial en el derecho colombiano", Revista de Derecho Privado, n. ${ }^{\circ} 47$ (2012): 1-31, http://dx.doi.org/10.15425/redepriv.47.2012.06; Corte Suprema de Justicia de Colombia. Sala de Casación Civil. Sentencia del 19 de octubre de 2011, MP: William Namén.

33 "La prestación que consagra el artículo 1324 inciso 1, es irrenunciable antes de celebrarse el contrato o durante su ejecución; pero una vez este haya terminado por cualquier causa, es decir, cuando queda incorporado ciertamente al patrimonio del agente comercial ese derecho crediticio a la prestación, entonces no se ve motivo alguno para que, en tales circunstancias, no pueda renunciarlo y tenga que hacerlo efectivo necesariamente. Si esta prestación es un derecho disponible una vez terminado el contrato, resulta evidente, que para concederlo judicialmente es menester que el acreedor así lo solicite, pues mientras no haga especifica solicitud al respecto, el juez no puede hacer esa condenación." Corte Suprema de Justicia de Colombia. Sala de Casación Civil. Sentencia del 2 diciembre de 1980, MP: Germán Gerardo Zuluaga.

“Con otras palabras, el agente, en estrictez, no renunció al derecho que le reconoce el artículo 1324 del Código de Comercio, pues si así fuera, no se explicaría que en la misma cláusula se hubiere reconocido y, además, previsto la forma de hacerlo efectivo. Esa renuncia es necesario entenderla dentro del marco de la propia estipulación, la cual, a no dudarlo, explica las razones de la misma: '[...] a la terminación del contrato el representante no tendrá derecho a percibir la doceava parte del promedio de la comisión antes mencionada, por estarla devengando a medida que este contrato se vaya ejecutando'. Por eso, entonces, se habló de renuncia, no porque se quisiera inexorablemente burlar el derecho del agente, sino porque éste no podía, al finalizar el negocio jurídico, reclamar el pago de una obligación ya solucionada.

“Obsérvese que el Tribunal asumió - a ultranza - la defensa de la irrenunciabilidad de la prestación en comento, al punto que consideró que la renuncia había sido vestida con el ropaje del pago anticipado acordado por los contratantes. $Y$ aunque no se discute en el sub lite -ni siquiera por el recurrente- la solidez de la piedra de toque de su razonamiento, pues esta corporación, de antaño, ha predicado el carácter imperativo de la regla contenida en el artículo 1324 del estatuto mercantil (CLVI, 269 y CCXXXVII, vol. II, 1288) -aspecto éste que no hace parte de este pronunciamiento-, es incontestable que no fue acertada la conclusión a la que arribó el sentenciador en la interpretación de la cláusula, habida cuenta que el pago anticipado de la prestación no es -no puede ser- sinónimo de renuncia, sino, por el contrario, de cumplimiento de la prestación debida, hipótesis en extremo diversa": Corte Suprema de Justicia de Colombia. Sala de Casación Civil. Sentencia del 28 febrero de 2005, MP: Carlos Ignacio Jaramillo. 
con los Estados Unidos de América, país en el que la prestación en cuestión es de carácter supletivo, y, en consecuencia, renunciable, sorprendieron dos cosas.

Primero, un proyecto de ley que intentaba derogar el carácter imperativo de la regla ${ }^{35}$, pero que nunca vio la luz; $y$, segundo, una sentencia de la Corte Suprema de Justicia, con ponencia del entonces magistrado William Namén, que desconoció la jurisprudencia que unánimemente había sido hasta entonces formulada por la misma institución, cambiando la interpretación de la regla, tal como se transcribe a continuación:

La doctrina elaborada por la Corte en el año de 1980 respecto de imperatividad del precepto legal y la indisponibilidad del derecho a la prestación consagrada en el inciso primero del artículo 1324 del Código de Comercio, se inspiró en la prudente interpretación del orden público social o económico dentro del contexto que se estimó imperante entonces, caracterizado por la supremacía de los empresarios agenciados, la desprotección de los agentes, la presencia de relaciones de mercado asimétricas y situaciones inequitativas e injustas en intereses considerados bajo esa perspectiva vitales en la industria y el comercio, y que la Sala juzgó necesario tutelar [...].

[...] el concepto de orden público, es dinámico, mutable y cambiante, aunque no esencialmente variable y sus modificaciones se advierten en intervalos relativamente largos en el tiempo.

Con estos lineamientos, en lo tocante a la prestación consagrada en el inciso primero del artículo 1324 del Código de Comercio, menester rectificar la doctrina expuesta otrora por la Corte, para subrayar ahora, además de su origen contractual, al brotar, nacer o constituirse solo de la celebración y terminación por cualquier causa del contrato de agencia comercial, su carácter dispositivo, y por consiguiente, la facultad reconocida por el ordenamiento jurídico a las partes en ejercicio legítimo de su libertad contractual o autonomía privada para disponer en contrario, sea en la celebración, ya en la ejecución, ora a la terminación, desde luego que stricto sensu es derecho patrimonial surgido de una relación contractual de único interés para los contratantes, que en nada compromete el orden público, las buenas costumbres, el interés general, el orden económico o social del país, ni los intereses generales del comercio, si se quiere entendido en la época actual, sino que concierne lato sensu, a los sujetos de una relación jurídica contractual, singular, específica, individual, particular y concreta, legitimadas para disciplinar el contenido del contrato y del vínculo que las ata, por supuesto, con sujeción a las directrices normativas ${ }^{36}$ [énfasis agregado]. 
En otras palabras, según este fallo, la consideración de si la regla es o no de orden público no depende de sí misma, sino de aspectos coyunturales y económicos, cuyas consecuencias legales definirá el juez de turno, a su completa conveniencia.

Para algunos, esta nueva interpretación del artículo 1324 del Código de Comercio constituye una "labor hermenéutica el papel social dinamizador de la jurisprudencia" ${ }^{37}$, llegando incluso a ser considerada como una sentencia "hito" en nuestro sistema jurídico ${ }^{38}$. Sin embargo, disentimos de considerar "hito" a un fallo en el que un juez abre los caminos para que el Tratado de Libre Comercio con los Estados Unidos pueda negociarse con mayor facilidad, sin pensar en las consecuencias que trae tal interpretación para los demás contratantes, en particular aquellos que comercializan sus productos con países de la Unión Europea ${ }^{39}$.

En efecto, como máxima autoridad del poder judicial, todo juez de la Corte Suprema de Justicia debería ser consciente de que los comerciantes colombianos no solo negocian con los Estados Unidos de América. Es más: no es este el único país con el que se hayan celebrado tratados de libre comercio. En efecto, a la fecha, Colombia tiene quince tratados de este tipo vigentes ${ }^{40}$. Tal vez, el segundo en mayor importancia es el que celebró con la Unión Europea.

Por esta razón, pese a lo extensa de la sentencia del exmagistrado Namén, se extraña en ella un análisis de derecho comparado sobre la prestación denominada "cesantía mercantil" en el contrato de agencia comercial. Dos ejemplos muy importantes sobre el carácter de orden público de este tipo de prestación existen. El primero, y tal vez el de mayor relevancia, es el de la Unión Europea; el segundo, el del Código de Comercio alemán.

En efecto, de acuerdo con la Directiva del Consejo del 18 de diciembre de 1986 , relativa a la coordinación de los derechos de los estados miembros en lo referente a los agentes comerciales independientes (86/653/CEE), este tipo de prestación es de orden público. De la misma manera, esta regla se encuentra en el Código de Comercio alemán, la sección 89b establece las condiciones para que, al finalizar el contrato de agencia, dicha prestación sea exigible, entre las cuales se

Hurtado-Palomino, "La influencia del TLC", 277.

Diana Carolina García Novoa, Kelly Lorena Rodríguez Aguilar y María Lourdes Solano Cera, “Análisis de la sentencia hito de la Corte Suprema de Justicia Sala de Casación Civil M. P. William Namén sobre cesantía comercial en la agencia mercantil a la luz del tratado de libre comercio con Estados Unidos" (tesis de Especialización en Derecho Comercial, Pontificia Universidad Javeriana, 2014), 1, https:// repository.javeriana.edu.co/handle/10554/14894.

9 En este punto, preferimos mantener la tradición en el sentido de que un fallo "hito", por el contrario, debería ser aquel que aporte riqueza y solidez en la interpretación de una regla de derecho existente. 
encuentra justamente que sea irrenunciable: "(4) The claim to indemnity cannot be excluded in advance" ${ }^{41}$.

Todo esto muestra que el mal llamado fallo "hito" de 2011 nos pone frente a una realidad muy difícil de comprender: si se tratase de un agente comercial colombiano, contratado por una empresa europea para ejecutar dicho contrato de agencia en Colombia, de acuerdo con el fallo de la Corte Suprema de Justicia de 2011, dicha prestación sería renunciable, esto es, no sería de orden público. Sin embargo, si un colombiano contrata a un agente comercial europeo para que ejecute el contrato de agencia en el espacio económico de la Unión Europea, éste no puede renunciar a la prestación que le correspondería por la terminación del contrato, debido a que esta regla es de orden público ${ }^{42}$. a reasonable indemnity from the principal, after termination of the agency contract, if and to the extent that

1. The principal continues to derive substantial benefits, even after termination of the agency contract, from business relations with new customers brought by the commercial agent, and

2. The payment of an indemnity is equitable having regard to all the circumstances and, in particular, the commission lost by the commercial agent on the business transacted with such customers.

If the commercial agent has so significantly increased the volume of business with a customer that it is economically equivalent to the acquisition of a new customer, it shall be deemed equal to the acquisition of a new customer.

(2) The indemnity shall amount to not more than one year's commission or other annual remuneration calculated on the basis of the commercial agent's average earnings for his activities over the preceding five years; if the agency contract goes back less than five years, the average for the period of activity shall be determinative.

(3) The claim to indemnity shall not arise if

1. the commercial agent has terminated the agency contract, unless the conduct of the principal gave justified grounds for doing so, or the commercial agent cannot reasonably be expected to continue his activities on account of his age or of illness, or

2. the principal has terminated the agency contract and there was a compelling reason for such termination owing to culpable conduct on part of the commercial agent, or

3. a third party enters into the agency contract in place of the commercial agent on the basis of an agreement between the principal and the commercial agent; such agreement cannot be made prior to the termination of the agency contract.

(4) The claim to indemnity cannot be excluded in advance. It must be asserted within one year after termination of the agency contract".

42 En este sentido, pero con un contratante estadounidense, se emitió un fallo de gran importancia en la materia: "Articles 17 and 18 of Directive 86/653 on the coordination of the laws of the Member States relating to selfemployed commercial agents, which guarantee certain rights to commercial agents after termination of agency contracts, must be applied where the commercial agent carried on his activity in a Member State although the principal is established in a non-member country and a clause of the contract stipulates that the contract is to be governed by the law of that country. The purpose of the regime established in Articles 17 to 19 of the Directive, which is mandatory in nature, is to protect, for all commercial agents, freedom of establishment and the operation of undistorted competition in the internal market, so that they must be applied where the situation is closely connected with the Community: Judgment of the Court (Fifth Chamber) of 
La excesiva concesión que hizo el fallo de 2011 con los contratos de agencia celebrados con los Estados Unidos lleva a una contradicción de la aplicación de la regla, tristemente en demérito de los contratantes colombianos que contratan con países de la Unión Europea. Aquí la falta de reciprocidad es evidente. Interpretación que, además, lleva al traste con lo que en la primera parte de este artículo estudiamos como un gran desarrollo jurisprudencial, consistente en que una de las características de las cláusulas abusivas es que, por su origen, son impuestas a los agentes comerciales colombianos que ejercerán sus funciones en Colombia, por el contratante que tiene mayor poder económico, para el caso las empresas de la Unión Europea. En suma, un verdadero fracaso de la protección de las cláusulas abusivas en los contratos de adhesión ${ }^{43}$.

Como lo veíamos, este tipo de relación genera un desequilibrio normativo importante entre las partes, en particular cuando se trata de la denominada "cesantía mercantil" del contrato de agencia, ya que si bien el agenciado que está sujeto a cumplir dicha prestación en su propio país, sin siquiera percatarse de cuál es la legislación vigente en Colombia, se la impone al agente colombiano; violando por ende la buena fe en sentido objetivo, y, si se le diera en estricto sentido el valor que tiene el fallo de 2011, esto es, una opinión aislada y coyuntural de la Corte, se podría comprender que estipulaciones de este tipo son absolutamente nulas por contrariar el orden público colombiano.

\section{Conclusión}

En conclusión, pese al gran esfuerzo realizado por la jurisprudencia y la doctrina en función de proteger a los comerciantes de contratos que les fueran asimétricos, la falta de coherencia en las decisiones de la Corte Suprema de Justicia de los últimos tiempos hace necesario pensar en la pertinencia de extender la protección a los comerciantes por la vía legislativa. Sin embargo, más allá de ello, para que sea

9 November 2000. - Ingmar GB Ltd v Eaton Leonard Technologies Inc. - Reference for a preliminary ruling: Court of Appeal (England \& Wales) - United Kingdom. - Directive 86/653/EEC - Selfemployed commercial agent carrying on his activity in a Member State - Principal established in a non-member country - Clause submitting the agency contract to the law of the country of establishment of the principal. - Case C-381/98".

43 Carlos Pizarro Wilson. "El fracaso de un sistema: análisis empírico y dogmático del control de cláusulas abusivas en contratos por adhesión / The failure of a system: Empiric and dogmatic analysis of control over unfair terms in contracts of adhesion". Revista de Derecho 20, n. ${ }^{\circ} 2$ (2007): 31-47, http://dx.doi.org/10.4067/S0718-09502007000200002. 
efectiva, esta protección requiere contratantes que comprendan las reglas en las que se basa la igualdad contractual, así como que los jueces de cortes supremas de Justicia luchen por la identidad y la armonía del sistema del cual hacen parte como máxima autoridad en la interpretación de las reglas de derecho de su sistema, en lugar de plegarse a tendencias internacionales de conveniencia meramente coyuntural y transitoria, ya que, como bien decía el maestro Antonio Rocha Alvira, un juez de la Corte Suprema de Justicia "está llamado a colaborar desde semejante altura en la más fecunda de las actividades públicas que es la realización de la justicia”"44.

\section{Referencias}

Bianca, Massimo. Derecho civil, El contrato. Traducido por Fernando Hinestrosa y Edgar Cortés, vol. 3. Bogotá: Universidad Externado de Colombia, 2007.

Calais-Auloy Jean y Temple Henri. Droit de la Consommation. Paris: DaIloz, 2015.

Corte Suprema de Justicia de Colombia. Sala de Casación Civil. Sentencia del 2 diciembre de 1980, MP: Germán Gerardo Zuluaga.

Corte Suprema de Justicia de Colombia. Sala de Casación Civil. Sentencia del 2 de febrero de 2001. MP: Carlos Ignacio Jaramillo Jaramillo.

Corte Suprema de Justicia de Colombia. Sala de Casación Civil. Sentencia del 28 febrero de 2005. MP: Carlos Ignacio Jaramillo.

Corte Suprema de Justicia de Colombia. Sala de Casación Civil. Sentencia del 19 de octubre de 2011. MP: William Namén.

Corte Suprema de Justicia de Colombia. Sala de Casación Civil. Sentencia del 24 de febrero de 2015. MP: Jesús Vall de Rutén Ruiz.

Escobar Sanín, Gabriel. Negocios de Sustitución, tomo I. Bogotá: Universidad Externado de Colombia, 1987.

García Novoa, Diana Carolina, Rodríguez Aguilar, Kelly Lorena y Solano Cera, María Lourdes. "Análisis de la sentencia hito de la Corte Suprema de Justicia Sala de Casación Civil M. P. William Namén sobre cesantía co-

Antonio Rocha Alvira. "Discurso en el homenaje que con motivo de la exaltación del Doctor Fernando Hinestrosa Daza a la magistratura de la Corte Suprema de Justicia", en Al Sr. Dr Antonio Rocha Alvira, Homenaje de la Universidad Externado de Colombia (Bogotá: Universidad Externado de Colombia, 1979), 171. 
mercial en la agencia mercantil a la luz del tratado de libre comercio con Estados Unidos". Tesis de Especialización en Derecho Comercial, Pontificia Universidad Javeriana, 2014. https://repository.javeriana.edu.co/ handle/10554/14894.

Giraldo Bustamante, Carlos Julio. "La agencia comercial en el derecho colombiano". Revista de Derecho Privado, n. 47 (2012): 1-31. http:// dx.doi.org/10.15425/redepriv.47.2012.06.

Gual Acosta, José Manuel. Cláusulas de irresponsabilidad. Entre asimetría, equilibrio y abusividad. Bogotá: Universidad Católica, 2015.

Gual Acosta, José Manuel. "El control sobre las cláusulas abusivas un régimen en evolución”. IUSTA, n. ${ }^{\circ}$ 30, (2009): 15-44. https://doi. org/10.15332/s1900-0448.2009.0030.01.

Gual Acosta, José Manuel. "Las cláusulas abusivas - Evolución hacia una noción". Revista Verba luris 11, n. ${ }^{\circ} 36$ (2016): 113-134. https://doi. org/10.18041/0121-3474/verbaiuris.36.1017.

Hurtado-Palomino, José Vicente. "La influencia del TLC con Estados Unidos en la evolución del alcance del concepto de orden público: la renunciabilidad de la mal llamada cesantía comercial". Díkaion Revista de Fundamentación Jurídica 21, n. ${ }^{\circ} 1$ (2012): 255-284. DOI: 10.5294/ dika.2012.21.1.8.

Judgment of the Court (Fifth Chamber) of 9 November 2000. - Ingmar GB Ltd v Eaton Leonard Technologies Inc. - Reference for a preliminary ruling: Court of Appeal (England \& Wales) - United Kingdom. - Directive $86 / 653 /$ EEC - Self-employed commercial agent carrying on his activity in a Member State - Principal established in a non-member country Clause submitting the agency contract to the law of the country of establishment of the principal. - Case C-381/98.

Lete, Javier. "Les conditions générales des contrats dans le projet espagnol de réforme du droit des obligations". En Les clauses abusives. Coordinado por Yves Picod, Denis Mazeaud y Elena Lauroba. Perpignan: Société de Législation Comparée, 2012, 53-58.

Martínez-Cárdenas, Betty. "Protección del consentimiento y reglas especiales del consumo: La lucha interminable contra las cláusulas abusivas". En Condiciones generales de la contratación y cláusulas abusivas. Coordinado por Francisca Barrientos Camus. Santiago: Ediciones Universidad Diego Portales, 2014, 69-81.

Martínez-Cárdenas, Betty y Tapias-Rocha, Hernando. "La transformación del derecho privado en Colombia”. Revista de Derecho, n. ${ }^{\circ} 45$ (2016): 3258. http://dx.doi.org/10.14482/dere.45.7970. 
Ministerio de Comercio. Acuerdos TLC Colombia. 2018. http://www.tlc. gov.co/acuerdos/vigente.

Monsalve-Caballero, Vladimir y Rodado-Barreto, Diana Paola. "La integración de la buena fe objetiva en la etapa de formación de los contratos de consumo". Vniversitas 60, n. ${ }^{\circ} 122$ (2011): 483-517. https://doi. org/10.11144/Javeriana.vj60-122.ibfo.

Narváez, José Ignacio. Introducción al Derecho Mercantil. Bogotá: Ediciones Bonnet, 1976.

Pérez Forero, Andrea Carolina. "Cláusulas abusivas y su regulación a la luz de la Ley 1480 de 2011: ¿compatibilidad o dicotomía?” Prolegómenos 16, n. ${ }^{\circ} 32$ (2013): 159-174. https://doi.org/10.18359/dere.766.

Pérez Vives, Álvaro. Comentarios al Código de Comercio, vol. 1. Bogotá: Colegas, 1980.

Picod, Yves. "Les clauses abusives dans les projects de réforme français". En Les clauses abusives. Coordinado por Yves Picod, Denis Mazeaud y Elena Lauroba. Perpignan, Société de Législation Comparée, 2012, 43-58.

Pizarro Wilson, Carlos. "El fracaso de un sistema: análisis empírico y dogmático del control de cláusulas abusivas en contratos por adhesión". Revista de Derecho 20, n. ${ }^{\circ} 2$ (2007): 31-47. http://dx.doi.org/10.4067/ S0718-09502007000200002.

Rocha Alvira, Antonio. "Discurso en el homenaje que con motivo de la exaltación del Doctor Fernando Hinestrosa Daza a la magistratura de la Corte Suprema de Justicia". En Al Sr. Dr. Antonio Rocha Alvira, Homenaje de la Universidad Externado de Colombia. Bogotá: Universidad Externado de Colombia, 1979, 171-179.

Rocha Alvira, Antonio. Lecciones sobre Derecho Civil Obligaciones. Actualizado por Betty Mercedes Martínez-Cárdenas. Bogotá, Universidad del Rosario, 2009.

Rodríguez Yong, Camilo. Una aproximación a las cláusulas abusivas. Bogotá: Universidad del Rosario y Legis, 2013.

Tribunal Superior de Medellín. Sentencia del 6 de diciembre de 1978, MP: Horacio Montoya.

Valette-Ercole, Vanessa. "Les clauses abusives en droit de la consommation". En Les clauses abusives, approches croiseés franco-espagnoles. Coordinado por Yves Picod, Denis Mazeaud y Elena Lauroba. Paris, Sociétée de Législation Comparée, 2012, 169-179. 